Peeters, M.G.P., Delnoij, D.M.J., Friele, R.D. Stronger, but not (yet) an equal. The use of quality improvement instruments and strategies by patient organisations in the Netherlands. Social

\begin{tabular}{|l|l|}
$\begin{array}{l}\text { Postprint } \\
\text { Version }\end{array}$ & 1.0 \\
\hline Journal website & http://www.sciencedirect.com/science/article/pii/S0277953614003372 \\
\hline Pubmed link & $\underline{\text { http://www.ncbi.nlm.nih.gov/pubmed/24949981 }}$ \\
\hline DOI & $10.1016 /$ j.socscimed.2014.05.043
\end{tabular}

This is a NIVEL certified Post Print, more info at http://www.nivel.eu

\title{
Stronger, but not (yet) an equal. The use of quality improvement instruments and strategies by patient organisations in the Netherlands
}

\author{
M.G.P. PEETERS ${ }^{\mathrm{A},}$ D.M.J. DELNOIJ ${ }^{\mathrm{A}, \mathrm{B},}$ R.D. FRIELE ${ }^{\mathrm{A}, \mathrm{C}}$ \\ a Tranzo, Scientific Center for Care and Welfare, Faculty of Social and Behavioural \\ Sciences, Tilburg University, PO Box 90153, 5000 LE Tilburg, The Netherlands \\ ${ }^{b}$ Dutch Institute for Quality in Health Care, PO Box 320, 1110 AH Diemen, The Netherlands \\ ${ }^{c}$ NIVEL, The Netherlands
}

\begin{abstract}
This article deals with the questions what the benefits and limitations are of the instruments and strategies that patient organisations use to influence quality of care. The advocacy of patients' interests has become more important for patient organisations in recent years, which is partly due to Dutch health care policy reform. Thirty state funded quality improvement projects run by patient organisations between 2009 and 2012 have been analysed. The quality improvement instruments developed and used in these projects are concerned with: standardization and standard setting (What is good care?); consultation, comparison and checking (What is the state of the care given?); and negotiating and advising (How can quality of care be improved?). The choice for these instruments is partly based on patient organisations' strategies of scientization, valuing institutionalized methods and valuing good relationships. We see that the development and use of these quality improvement instruments do strengthen patient organisation and therefore have internal identity and organisational effects. However, the external effects patient organisations can have by using these instruments and strategies is limited or at least insecure by lack of economic capital after the development phase and lack of negotiating power. The external effects of these instruments and strategies depend largely on a patient organisation's network and the willingness, degree of openness and policy of other stakeholders to cooperate. Therefore, these forms of patient participation remain vulnerable.
\end{abstract}


Peeters, M.G.P., Delnoij, D.M.J., Friele, R.D. Stronger, but not (yet) an equal. The use of quality improvement instruments and strategies by patient organisations in the Netherlands. Social Science \& Medicine: 2014, 115(aug), 56-63

\section{INTRODUCTION}

This article is concerned with empowerment of patients at the macro level, meaning the collective voice of patient organisations. The main activities of Dutch patient organisations have traditionally been to offer support, give information and to look after patients' interests. In recent years the latter activity seems to have become more important. One way of looking after patients' interest at a collective level, is to influence quality of care. Many projects to influence quality of care from patients' perspective have been set up. Patient organisations have participated in these projects. It is not yet clear, however, to what degree this participation has been successful, which leads to the following research question. What are the benefits and limitations of the instruments and strategies that patient organisations use to influence quality of care?

\section{THEORY}

One could state that 'the patient movement' in the Netherland cannot be characterised as such because it contains a large variety of types of organisations for many different diseases, syndromes and conditions (Berk et al., 2008, Nederland et al., 2003 and Schipaanboord et al., 2011). Traditionally, especially from the nineteen seventies and eighties onwards, collectivisation of patients and proxy took place with regard to mental illness, disabilities and chronic illness. In addition to these, more universal network and umbrella patient organisations have been founded. By the beginning of the twenty-first century hundreds of patient organisations were active that differed in size, in financial means, in contacts, in the groups they represent and in the degree to which they are professionalized (Berk et al., 2008, Kamphuis et al., 2012 and Nederland and Duyvendak, 2004). Their activities may be directed at strengthening their own organisation and members (internal effects) or at other stakeholders (external effects). Internal effects relate to both identity and organisation effects. A patient organisation tries to achieve identity effects when the sense of identity of a group or individual patients is reinforced, for example by organising support group meetings. Organisation effects are what a patient organisation is trying to achieve by improving the organisational structure of an organisation, by employing a professional administrator for example. External effects can be subdivided into the following four effects: 1) actions have a sensitizing effect when the patient organisation makes other parties aware of its demands or when these demands are put on the agenda; 2) actions have a procedural effect when a patient organisation manages to gain access to the decision-making process or when the organisation is (formally) recognized as a discussion partner; 3) actions have a substantial effect when the demands of a patient organisation are actually met, thus when patient representatives actually influence the decision-making process.; and 4) actions have a structural effect, when the socio-political opportunity structure for patient organisations changes ( Nederland et al., 2003).

Among other ways, patient organisations have tried to look after patients' interests by participation in the improvement of quality of care. In patient participation literature two types of reasons have been put forward as to why patient participation is considered valuable. The first values patient participation as a purpose in itself, such as the democratic right patients have to influence what they are affected by or the improvement of accountability within health care policy. Secondly, more instrumental reasons have been put forward that value participation as a means, such 
Peeters, M.G.P., Delnoij, D.M.J., Friele, R.D. Stronger, but not (yet) an equal. The use of quality improvement instruments and strategies by patient organisations in the Netherlands. Social Science \& Medicine: 2014, 115(aug), 56-63

as making use of the unique knowledge patients contribute in the form of experiential knowledge or improvement of the social basis for the implementation of new policies ( Boivin et al., 2009, Bovenkamp et al., 2010, Callahan, 2007 and Teunissen and Abma, 2010).

Reforms in Dutch health care policy have put more emphasis on the empowerment of patients. This is the result of the introduction of regulated competition in this field in 2006 (Health Insurance Act; Healthcare Market Regulation Act). To a certain extent the government has withdrawn and left more of the regulating and coordinating of the health care system to a 'power triangle' of insurers, providers and health care users in a regulated market system (Bouman et al., 2008, Raad voor Volksgezondheid en Zorg, 2010 and Schipaanboord et al., 2011). Health care providers and insurers are connected in the health care provider market. With the regulated competition introduced in 2006, health care providers are supposed to compete over price and quality (Bouman et al., 2008, Nederland et al., 2007 and Schipaanboord et al., 2011). Health care users are expected to be able to influence insurers and providers as consumers who have a choice in the health insurance market and in the health care provider market (Victoor et al., 2012). Giving individual patients more choice is however not assumed to suffice to empower patients. In order to enable health care users to function as well-informed, critical consumers, the focus lies on transparency. Transparency of price, quality and other health care characteristics is considered important (Bal, 2008 and Zuidgeest, 2011). In addition to this, patient influence is only expected to function when individual empowerment is accompanied by empowerment at a meso level (e.g. client councils) and at the macro level of patient organisations. For example, patient organisations can try to influence the quality criteria that insurers use to value the care offered by providers. In line with this policy, Dutch government has offered these organisations funding (Ministerie VWS, 2008-2009). The governmental scheme offers structural financing and project grants in order to create and support organisations that can function as 'strong representatives'. An independent counsel grants the subsidies, while the office work is carried out by Fund for Patients, Disabled and Elderly (PGO Fonds, from now on 'PDE Fund'). Consequently patient organisations should be able to function as a third party, which means they can negotiate and cooperate as an equal with health insurers and providers ( Arnstein, 1969 and Teunissen and Abma, 2010). In line with these developments Dutch patient organisations have taken all kinds of initiatives to influence quality of care in recent years. A number of these initiatives were subject of the analysis presented in this paper.

\section{Methods}

In order to analyse the benefits and limitations of the instruments and strategies that patient organisations use to influence quality of care, it was decided to analyse ongoing projects. Therefore, a number of projects run by patient organisations that were granted government subsidy in 2009 have been selected.

The research is concerned with the benefits and limitations of the instruments and strategies that patient organisations have chosen to influence quality of care.

Therefore, we selected patient participation projects with an external instrumental goal, which are directed at stakeholders outside of the patient movement who can influence quality of care. The external instrumental goal had to be concerned with quality of care. Applying this selection criterion was expected to lead to the inclusion 
Peeters, M.G.P., Delnoij, D.M.J., Friele, R.D. Stronger, but not (yet) an equal. The use of quality improvement instruments and strategies by patient organisations in the Netherlands. Social Science \& Medicine: 2014, 115(aug), 56-63

of a broad spectrum of quality improvement instruments. Whether or not quality of care for the represented patients will actually be improved in practice due to the development and use of quality improvement methods, is a question that goes beyond the scope of this article.

First, a broad selection of 57 projects was made according to this selection criterion and on the basis of the concise public information about the projects. Then, the PDE Fund asked the patient organisations permission to give us as researchers access to the official project documents. A few organisations did not react to the request for permission. A more precise selection was then made by screening the project descriptions in the subsidy requests made by the patient organisations. This procedure has led to the inclusion of 30 projects, of which an overview is giving in Appendix 1.

Five organisations run more than one project. The patient organisations that run the projects differ, in size, in financial means, in contacts, in the groups they represent and in the degree to which they are professionalized. All projects started in 2009 or 2010. While the majority of projects run until 2012, some had already been finished in 2010 or 2011. Other projects were extended beyond 2012. The data collection consisted of semi-structured interviews with 31 representatives of the patient organisations and an analysis of formal project documentation organisations were obliged to deliver (project plan, annual reports, and final report). One or more interviews were held, depending on the duration of the project. Some respondents represented more than one selected project and some projects were represented by more than one respondent. The respondents were the professionals or volunteers who were the main coordinators or organisers of the selected project. The following issues were addressed by the interviewer. How did the project develop up until the interview? What forms and levels of patient participation were adopted in the project, and how did this work out? Which quality improvement instruments were developed or implemented, and how did these work out? What other parties did you try to influence or try to cooperate with, and how did this work out? What does a patient organisation need in order to use the quality improvement instruments in question? How does the respondent expect the project to develop further? The semi-structured interviews with 31 respondents were recorded and fully transcribed. The interviews were done individually by two researchers. An analytical framework was developed and discussed by three researchers. One researcher actually did the categorizing and coding of material. During the analysis, this researcher discussed with the two others whether codes or categories needed to be added, removed or reformulated. Two discussion meetings with respondents and other patient representatives were held as a member check. The first session (26-05-2011) after one year, to check whether the issues addressed in the research were relevant for patient organisation and the second session (16-04-2013) towards the end of the research to discuss preliminary results. The interview transcripts and the formal project documentation were analysed according to a theoretical framework of which the following three aspects will be addressed in this article.

First, the types of quality improvement methods used by patient organisations. Second, the strategies that lie behind the choice for these quality improvement methods. In other words, what the patient organisations hoped to achieve by use of these quality improvement methods. This is analysed in terms of the different types of external effects introduced above, that is sensitizing, procedural, substantial and 
Peeters, M.G.P., Delnoij, D.M.J., Friele, R.D. Stronger, but not (yet) an equal. The use of quality improvement instruments and strategies by patient organisations in the Netherlands. Social Science \& Medicine: 2014, 115(aug), 56-63

structural effects ( Nederland et al., 2003). And although only projects that aim at external effects have been selected for this study, internal effects (identity and organisation effects) are included as well because they can have a function as a secondary goal, or in the following phases of this study as unintended effects or alternative results. Third, the disadvantages, barriers, benefits and facilitators patient organisations encountered in the development, adoption or use of the quality improvement instruments in question.

\section{RESULTS}

\subsection{Types of quality improvement methods}

The analysis of project documentation and the interviews with patients' representatives show three main categories of quality improvement instruments with an external instrumental goal which have been deployed by patient organisations in the 30 selected projects: 1 ) instruments to state what good care is: standardization and standard setting, 2) instruments to determine the state of currently given care: consultation, comparison, and checking, and 3) instruments to improve quality of care: negotiating and advising. An overview is given in Appendix 1.

\subsubsection{Category 1: standardization and standard setting. What is good care?}

Setting standards is a method often used by Dutch patient organisations to express patients' perspective on quality of care and to establish the norm as set by patients. In this research 17 projects have included some form of standardization and standard setting. Among patient organisations it is in a way considered to be a basic document or set with regards to their quality improvement efforts. Quality criteria are a means to establish a group of patients' common needs and demands with regard to quality of care. A list of quality criteria is developed or used in 13 projects. Standards of care, which are developed in four projects, are designed as an instrument for people suffering from a chronic disease. Such a standard is supposed to offer a clear description of optimal care for patients suffering from a chronic disease, and the organisation of this care with a focus on the cooperation of multiple disciplines and integrated care. With this standard patients know what to expect from professional care givers, and should be able to take responsibility for the care they receive, to improve their quality of life with the limits of their chronic disease. This standard of care differs from a medical guideline in the sense that the latter is more technical and detailed, less broad and directed primarily at health care professionals ( Coordinatieplatform-zorgstandaarden, 2010).

\subsubsection{Category 2: consultation, comparison and checking. What is the state of the care given?}

In 25 projects a method is used to establish what the current state of the quality of care given to 'their patients' is.

A method (intended to be) used by 16 patient organisations in order to support patients' choice is to value a certain standard of care by comparing institutions, by issuing a mark of quality or to provide individual patients with a decisions tree or checklist. Whether an institution that provides care has met the standards, is supposed to be established by consulting patients and care providers directly through visitation, surveys, or indirectly by analysing data available through other sources. Six projects aim at the development of a Consumer Quality Index (from now on $C Q I)$, which measures the experiences individual patients have with health care 
Peeters, M.G.P., Delnoij, D.M.J., Friele, R.D. Stronger, but not (yet) an equal. The use of quality improvement instruments and strategies by patient organisations in the Netherlands. Social Science \& Medicine: 2014, 115(aug), 56-63

providers and health plans ( Delnoij et al., 2010). A CQI is an established instrument that produces quantitative scientific data. The Dutch Ministry of Health, Welfare and Sports has proposed the CQI as the national standard for measuring this national standard in 2006. The CQI is now an official trademark that indicates data have been collected according to the CQI Manual by a certified 'survey vendor'. The Centre for Consumer Experience in Health Care (CKZ) owns the trademark and cooperates with patient organisations in the development of CQI's for specific subgroups of patients.

Three organisations intend to establish the state of care given by letting teams consisting of patients and others like proxy or professionals, conduct visitations. This usually entails checking the providers' policies, consulting patients and professionals who respectively receive and provide care at a certain location, and actually visiting the locations.

\subsubsection{Category 3: negotiating and advising. How can the quality of care be improved?}

Negotiating and advising is a quality improvement method that is (intended to be) used or developed in 13 projects. This method is directed at institutions that provide care and at insurance companies. Improving the quality of care means improving the quality of care from patients' perspective. Since negotiating and advising usually is an end goal that is planned for the last phases of a project, this research can only give insight in the patients' organisations experienced in developing this method. Giving advice and negotiating in which way the quality of care could be improved, is part of most visitations and audits. Another form of this method entails discussing the quality criteria according to which insurers reimburse the costs of care for individual patients.

\subsection{Strategies}

In the interviews about these projects, patients' representatives expressed several strategies behind the application of the aforementioned methods. An overview of the strategies expressed per project is given in Appendix 1. The overview shows which strategies organisations have expressed themselves; respondents have not been asked whether they employ any of the strategies mentioned. For some organisations these reasons are part of a well-defined long term strategy, which entails all three categories of methods. Such a strategy can be to first establish the standards of care, then to consult patients whether the care they receive meets those standards, and finally negotiating which improvements a hospital should aim at in the following year. Other organisations however, seem to take one step at a time. They expect that the quality improvement method can be of value in the future, but is not clear yet in what way or how these future applications could be financed. Three types of strategies to apply one or more of the quality improvement methods set out above, were expressed most.

The first strategy was expressed by respondents with regards to 18 projects, which can be best described as a 'scientization strategy'. 'Scientization' is, a concept to describe patient organisations' effort to scientifically or systematically substantiate their input in order to gain authority ( Leahy et al., 2011). Many patient organisations, including large professional ones, have experienced that their contributions are often not taken seriously. Their main problem is that their contributions are set aside as being 'anecdotal'. By collecting their patients' 
Peeters, M.G.P., Delnoij, D.M.J., Friele, R.D. Stronger, but not (yet) an equal. The use of quality improvement instruments and strategies by patient organisations in the Netherlands. Social Science \& Medicine: 2014, 115(aug), 56-63

perspective in a scientific or at least systematic way they want to set a standard other stakeholders cannot set aside. In order to be more effective within the power triangle for they apply well established methods such as standards of care, the CQI or AIRE (Appraisal of Indicators through Research and Evaluation) ( Koning et al., 2007). The second strategy was expressed by project representatives with regards to 12 projects and can be best described as an institutionalized methods strategy. The strategy entails choosing well established instruments because they are established and institutionalized. Not having to start from scratch, learning from other patient groups' experiences, and having a better chance at government subsidies are important motives given by patient organisations in this regard. Seven organisations try to set the standard for quality improvement methods. These organisations cooperate in order to make their method the institutionalised method. These organisations also trusted on an institutionalized methods strategy.

The third strategy, which was expressed by respondents with regards to 14 projects, can be defined as a good relationship strategy. This means that the patient organisations have chosen instruments that enabled them to maintain or establish a good relationship with other stakeholders. This focus on a good relationship can also entail that instruments are used in such a way that other stakeholders are not offended. One project that included patient visitations for example, was directed at quality aspects such as friendliness rather than medical expertise in order to ensure the cooperation of medical specialists among other reasons.

\section{Disadvantages and barriers, benefits and facilitators.}

Patient organisations encounter several disadvantages, barriers, benefits and facilitators when they develop, adopt and use the quality improvement methods addressed in this paper. In part these aspects can be summed up by evaluating the underlying strategies.

Patient representatives usually consider cooperation with health care providers and insurers as a prerequisite for implementation.

"If you involve professionals in the development, you have done so much of the preparation and work already. Then, when the development is finished, all you still have to do is to score the goal" (Discussion meeting II, 2013, Patient representative) Aspects such as professional expectations, jargon and planning can be taken into consideration to improve the chance of having procedural and substantive effects. According to respondents patient's demands can be blurred when that which is achievable and expected by other interest groups, is taken into consideration already in the early stages of the development of a quality instrument. The distinction between minimal/realistic demands and the actually desired quality of care can become unclear. Activism can be held back when a patient organisation prioritizes a good relationship even when a particular issue might ask for an activist approach with regards to a certain interest group. Activism makes a patient organisation more visible for example.

"Sometimes when working on a project, I put a lot of effort in cooperation. But then, suddenly somebody else in the organisation shouts: "It's a disgrace. The national press has to know about this!” It make me think: "please don't break things”. That is difficult, as an organisation you have to be aware which approach is best in what situation” (Discussion meeting II, 2013, Patient representative) These conflicts of interest do occur within patient organisations or even within one project. Strategic planning is therefore needed. 
Peeters, M.G.P., Delnoij, D.M.J., Friele, R.D. Stronger, but not (yet) an equal. The use of quality improvement instruments and strategies by patient organisations in the Netherlands. Social Science \& Medicine: 2014, 115(aug), 56-63

A scientization strategy also has some clear benefits. Providing substantiated input meets the expectations of other parties. This strategy therefore undermines the often used argument that the patient organisation's input is 'anecdotal' which paves the way for external effects. It also has strong internal organisational and identity effects when a patient organisation can clearly put forward prioritised demands.

The drawback lies in the experience that this strategy is very demanding. The development of a scientific or systematic quality improvement instrument requires substantial economic capital in the form of money and man-hours, knowledge of research methods as cultural capital and access to members or even a larger patient group as social capital. This development consequently is a long term investment. Furthermore, the method is directive and certain issues or minority views might fade into the background. This sometimes makes it difficult for organisations to account for the capital put into it towards their own members. Expectation management by the project coordinators is sometimes required.

The benefit of choosing an institutionalized method lies in the fact that stakeholders are more susceptible to instruments they already know from dealing with other patient groups. A risk lies in the fact that a method with a strict protocol will be more directive, as is the case with scientific methods. Furthermore, a patient organisation might choose an institutionalized method rather than a method that fits its particular needs at a certain time. Also, the discussion might increase with regards to an instrument that has a chance of becoming 'the standard' because the stakes are getting higher.

Although the quality improvement methods in the selected projects pose some risks and have limitations, they do tend to have identity and organisational internal effects. Most respondent thus feel that having these instruments has fortified their organisations, but the data also points out two obstacles to the external effects that can actually be achieved by use of these instruments.

\subsubsection{Barrier 1: economic capital}

The first obstacle is the economic capital needed to implement and maintain the quality improvement instruments. According to respondents it is difficult for patient organisations to finance quality improvement in a structural way or to receive successive project funding, especially now Dutch government has changed her funding policy regarding patient participation (Ministerie van Volksgezondheid, 2011 and Schippers, 2011). Developing instruments is however just the start, as is illustrated by this quote.

"A three-year programme is long, but only a good start, not more than that. We have been working on the basics. What we have now is good, but only a basis for further developments. The real game starts now.” (2012, Project 18.6)

The lack of economic capital puts the cultural and social capital needed for implementation and maintenance at risk. An employee that has to leave, for example, cannot leave behind specific knowledge about a method, tacit knowledge and his personal network with regards to the instrument.

\subsubsection{Barrier 2: negotiating power}

The second obstacle brought forward by respondents is a lack of negotiating power and subsequent dependency on other parties. This is not a new problem for Dutch patient organisations (Bovenkamp, 2010 and Bovenkamp et al., 2010). In order to make the next steps towards procedural and substantive effects, patient organisations 
Peeters, M.G.P., Delnoij, D.M.J., Friele, R.D. Stronger, but not (yet) an equal. The use of quality improvement instruments and strategies by patient organisations in the Netherlands. Social Science \& Medicine: 2014, 115(aug), 56-63

seem to depend largely on their network and the willingness, degree of openness and policy of other stakeholders to cooperate since health insurers and health care providers are not obliged to cooperate or negotiate with patient organisations. This is illustrated by respondents that tried to influence health care insurers.

"We noticed that insurers differ greatly in the way they deal with patient organisations. Insurer $\mathrm{x}$ was very active in trying to involve patient organisations in all kinds of projects, while insurer y had no contact with patient organisations before the project started. Whether or not we have contact with an insurer depends greatly on the particular people working for the insurer." (2011, PT 19.0)

"Our input is very important; they are aware of that. It is just that quality criteria are not prioritised by insurers at the moment. They have so many issues to deal with. (...) You see, insurers do include quality criteria, but only with regards to conditions which affect many patients. Criteria for rare diseases are not really taken into consideration." (2012, PT18.0)

Added to these concerns, is the risk that in terms of image some patient groups might be of more interest to other parties than others.

\section{DISCUSSION}

Dutch patient organisations have participated in many projects in recent years to influence the improvement of quality of care from patients' perspective. Thirty projects that were set up to have an external effect which were run by patient organisations between 2009 and 2012 were analysed. Partly due to this selection, this research seems to shed light on the part of the patient movement that adopts the culture of 'corporate rationalizers', a concept first introduced by sociologist Alfords in 1975 which has been applied to the current western health care system by Williamson (Alfords, 1975, Williamson, 2008 and Williamson, 2010). Williamson describes corporate rationalizers as 'a diverse set of people including officials in government health departments, executive managers in health services and health service institutions; public health doctors (as distinct from clinicians), health economists, deans of medical schools and many other academics and commentators on healthcare', who are 'concerned with populations of patients and with the costeffective use of resources, not with individual patients' and who have gotten more influential in recent years (Williamson, 2010). The selected patient organisations have chosen strategies and quality improvement instruments that fit into this culture. An institutionalized method strategy is chosen, for example, to make use of support and government funding possibilities. Or, a scientization strategy because patient organisations want their input to be taken seriously. Finally, a good relationship strategy supports the long term strategy aimed at cooperation, which also fits in this culture. Choosing methods on the basis of these strategies and in accordance with a culture of corporate rationalizers seems to have both benefits and risks and limitations. With regards to these strategies, the following benefits and risks/limitations can be derived from this research.

Literature on lobby groups and participation shows why trying to fit in the culture of corporate rationalisers might be a good approach for patient organisations. A scientization strategy, for example, is in line with the tendency in health care and other fields in Western society to value scientific knowledge over experiential knowledge. In order to function as an activist group, making their contribution more systematic and scientific is an important way for patient organisations to put pressure 
Peeters, M.G.P., Delnoij, D.M.J., Friele, R.D. Stronger, but not (yet) an equal. The use of quality improvement instruments and strategies by patient organisations in the Netherlands. Social Science \& Medicine: 2014, 115(aug), 56-63

on other stakeholders (Leahy et al., 2011, Peper, 1998, Stone, 2002 and Winter and Steger, 1998). Furthermore, choosing an institutionalised method, is in line with literature that shows the success rates for activists are higher when a method is routinized, well-known, available, and undisputed (Miller and Sarat, 1980-1981 and Peeters, 2007). The good relationship strategy is also described as having some clear benefits. A great benefit is that a focus on cooperation and consensus is in line with the Dutch tendency to organise participation according to the neo-corporatist model, which focuses on input through formal decision-making procedures. Traditionally, most patient organisations make less use of more confrontational methods such as legal procedures, naming and shaming through mass media as a form of outside pressure, or mobilising their followers to form a consumer boycott (Bovenkamp et al., 2010 and Winter and Steger, 1998).

Participation researchers, among which several authors that have studied patient participation in the Netherlands, have however pointed out risks in (striving for) forms of participating that are demanding or aimed at consensus. Many patient organisations lack the time, mental or physical capacities, resources, knowledge and expertise to effectively make use of all the offers made to participate in formal decision-making procedures, while the procedures are not always designed to enable more than symbolic participation. A situation of inequality might arise between those that are able and not able to participate on both a collective and an individual level. For patient organisations and individual patients, participation can become a necessity and obligation rather than a choice in order to guarantee sufficient quality of care. The predominant organisation of participation according to the neocorporatist model stimulates consensus and cooperation at the cost of confrontation, enclosure at the cost of public and outside pressure, and semi-professionalization at the cost of pressing ahead patients' genuine demands and concerns. The participation of members of (umbrella) patient organisations in formal decision-making procedure raises questions about the representativeness and accountability of those participating. This poses the question whether striving for the most demanding, institutionalised and active forms of participation is always in the best interest of both individual patients and patient groups (Bovenkamp et al., 2008, Bovenkamp and Trappenburg, 2009, Bovenkamp et al., 2010, Broerse et al., 2010, Callahan, 2007, Leahy et al., 2011, Mol, 2006, Peeters, 2007, Sok et al., 2009, Trappenburg and Bovenkamp, 2008 and Tritter, 2006).

This research has shown similar concerns among patient organisations about the risks and limitations with regards to the particular quality improvement methods and strategies that have been analysed. The majority of these methods and strategies seem to have strengthened the patient organisations as such. The full extent of the external effects or the lack thereof is however not yet clear. Will the knowledge and methods patient organisations have invested in function as a form of cultural capital that makes patient organisations more influential and independent? On the one hand, risks such as symbolic participation or questions about accountability and representativeness seems to be less prominent since these organisations have strengthened their input. Issues such as the resources needed to sustain, update and implement the developed quality improvement methods, on the other hand, seem to be even more pressing since these methods are part of a long term investment. Moreover, the focus on long term investments and cooperation requires a long term 
Peeters, M.G.P., Delnoij, D.M.J., Friele, R.D. Stronger, but not (yet) an equal. The use of quality improvement instruments and strategies by patient organisations in the Netherlands. Social Science \& Medicine: 2014, 115(aug), 56-63

balance between that which patient organisations actually want and that which is considered acceptable by other parties.

\subsection{Strengths and limitations of this study}

This study's strength lays in the comparison of similar quality improvement instruments by different kinds of patient organisations over a longer period of time. The analysis is, however, limited to organisations that applied for and received a government grant for their project. A consequence of the choice for subsidized projects, is that this research does not give insight in the functioning as a third party of the whole spectrum of Dutch patient organisations. It can be presumed that organisations successful at receiving a grant are probably also more successful at influencing quality of care. Organisations not able to receive a grant or financially independent organisations that do not apply for a grant are not included in this study. This means this article sheds light on beneficial and limiting factors patient organisations in the Netherlands encounter trying to influence quality of care without claiming to analyse the current degree of influence of the whole spectrum of Dutch patient organisations.

\section{CONCLUSION}

This article deals with the question what the benefits and limitations are of the instruments and strategies that patient organisations use to influence quality of care. This question is relevant because participation in quality of care has become more important for Dutch patient organisations. This is partly due to changes in Dutch health care policy that require these organisations to function more and more as a third party, meaning they can negotiate and cooperate as an equal with health care providers and insurers. Out of a group of projects that received government funding, 30 ongoing projects were selected with an external instrumental goal, which are directed at stakeholders outside of the patient movement who can influence quality of care. The quality improvement methods developed and used in the selected projects were divided into three categories: 1) Standardization and standard setting. What is good care? (17 projects); 2) Consultation, comparison, and checking. What is the state of the care given? (25 projects); 3) Negotiating and advising. How can the quality of care be improved? (13 projects). Partly due to the selection criteria, this research seems to shed light on patient organisations that chose quality improvement methods on the basis of three main strategies that resemble the culture of 'corporate rationalizers'. As such, this research also sheds light on patient organisations that handle participation as a long term investment.

The good relationship strategy means that patient organisations choose instruments that enabled them to maintain or establish a good relationship with other stakeholders. Beneficial is that this strategy is in line with the Dutch tendency to arrange decision-making through cooperation and consensus. Furthermore, this strategy enables implementation as it is focused on the involvement of other interest group at an early stage of instrument development. Taking other interest into consideration may however blur the real demands and interests patients have and hold back activism. A scientization strategy, making patient input research-based or systematic, is beneficial for collective patient influence as it undermines the argument that patient input is 'anecdotal' and it uses the authority that science and research have in Western society. The fact that working according to this strategy does requires substantial economic, social and cultural capital is nevertheless a 
Peeters, M.G.P., Delnoij, D.M.J., Friele, R.D. Stronger, but not (yet) an equal. The use of quality improvement instruments and strategies by patient organisations in the Netherlands. Social Science \& Medicine: 2014, 115(aug), 56-63

drawback. Moreover, the method can be directive and may put issues in the background. Third, the institutionalized methods strategy entails choosing well established instruments because they are established and institutionalized. This strategy can benefit patient organisations' influence since the chance of achieving external effects is higher with a well-known and undisputed method. Again, the risk lies is the method and the funding possible are directive rather than the needs of a patient group at a particular time.

These quality improvement instruments are predominantly developed as a long term investment, which increases the need for additional or structural economic capital to actually implement and maintain them. This proves to be difficult for patient organisations, which limits their capacity to influence quality of care. A corresponding limitation lies in the lack of negotiating power. Thus, although patient organisations seem to have developed the right instruments to influence quality of care, there are obstacles that make fulfilling this role insecure in practise. These organisation are, in other words, ready to contribute substantively to quality improvement but dependent on other parties to actually do so.

\section{ACKNOWLEDGEMENTS}

Although D. Delnoij participated in this research as Professor at Tilburg University, it should be noted that during the study she also acted as director of the Centre for Consumer Experience in Health Care (CKZ). The CKZ participated in several of the projects that were selected for this research.

APPENDIX 1. OVERVIEW SELECTED PROJECTS.

\begin{tabular}{|c|c|c|c|}
\hline $\begin{array}{l}\text { Patient organisation } \\
\text { (project codes) }\end{array}$ & Selected projects & $\begin{array}{c}\text { Type of } \\
\text { instrument }^{\mathrm{a}}\end{array}$ & Strategies ${ }^{b}$ \\
\hline $\begin{array}{l}\text { National Platform for } \\
\text { Mental Health Care } \\
\text { (PT7.0) }\end{array}$ & $\begin{array}{l}\text { Mental health care } \\
\text { purchase from clients' } \\
\text { perspective. }\end{array}$ & $00 ; 14 ; 35 ; 41$ & $11 ; 13$ \\
\hline $\begin{array}{l}\text { Dutch Breast Cancer } \\
\text { Association (PT9.1) }\end{array}$ & \multirow{4}{*}{$\begin{array}{l}\text { Standardised and } \\
\text { concentrated care for } \\
\text { rare disorders. }\end{array}$} & 11 & $10 ; 12$ \\
\hline $\begin{array}{l}\text { Dutch Addison and } \\
\text { Cushing Association } \\
\text { (PT9.3) }\end{array}$ & & 11 & $12 ; 14$ \\
\hline $\begin{array}{l}\text { Down's Syndrome } \\
\text { Foundation (PT9.4) }\end{array}$ & & 35 & 12 \\
\hline \begin{tabular}{|l} 
Cancer Diagnosis \\
Foundation (PT9.5)
\end{tabular} & & 11 & $10 ; 14$ \\
\hline $\begin{array}{l}\text { Dutch Association for } \\
\text { Graves' Patients } \\
\text { (PT11.1) }\end{array}$ & \multirow{3}{*}{$\begin{array}{l}\text { Making effective use of } \\
\text { experiential knowledge. }\end{array}$} & $12 ; 35$ & $10 ; 11 ; 14$ \\
\hline $\begin{array}{l}\text { Dutch Thyroid Gland } \\
\text { Foundation (PT11.2) }\end{array}$ & & 12; 35 & $10 ; 11 ; 14$ \\
\hline $\begin{array}{l}\text { Pelvic Girdle Patients } \\
\text { Foundation (PT11.3) }\end{array}$ & & $11 ; 12 ; 35$ & $11 ; 12 ; 14$ \\
\hline
\end{tabular}


Peeters, M.G.P., Delnoij, D.M.J., Friele, R.D. Stronger, but not (yet) an equal. The use of quality improvement instruments and strategies by patient organisations in the Netherlands. Social Science \& Medicine: 2014, 115(aug), 56-63

\begin{tabular}{|c|c|c|c|}
\hline $\begin{array}{c}\text { Patient organisation } \\
\text { (project codes) }\end{array}$ & Selected projects & $\begin{array}{c}\text { Type of } \\
\text { instrument }^{\mathrm{a}}\end{array}$ & Strategies \\
\hline $\begin{array}{l}\text { Dutch Klinefelter } \\
\text { Association (PT11.4) }\end{array}$ & & 12,13 & 14 \\
\hline $\begin{array}{l}\text { Dutch Ehlers-Danlos } \\
\text { Patient Association } \\
\text { (PT11.5) } \\
\end{array}$ & & $12 ; 35$ & $11 ; 12$ \\
\hline $\begin{array}{l}\text { National Federation of } \\
\text { Independent } \\
\text { Consumer- and } \\
\text { Advocate-driven } \\
\text { Mental Health Self- } \\
\text { Help (PT16) } \\
\end{array}$ & Quality of care hallmark & |33; 35 & 13 \\
\hline $\begin{array}{l}\text { Asthma and Lung } \\
\text { disease Patients } \\
\text { Association (PT18.1) } \\
\end{array}$ & \multirow{7}{*}{ Quality in sight } & \multirow{7}{*}{$\begin{array}{l}12 ; 14 ; 20 \\
21 ; 30 ; 35 \\
41 ; 42\end{array}$} & \multirow{7}{*}{$\begin{array}{l}00 ; 10 ; 11 ; \\
12\end{array}$} \\
\hline $\begin{array}{l}\text { Heart and Vascular } \\
\text { Group (PT18.2) }\end{array}$ & & & \\
\hline $\begin{array}{l}\text { Dutch Federation of } \\
\text { Cancer Patients } \\
\text { Associations (PT18.3) }\end{array}$ & & & \\
\hline $\begin{array}{l}\text { Rheumatics } \\
\text { Association (PT18.4) }\end{array}$ & & & \\
\hline $\begin{array}{l}\text { Dutch Association for } \\
\text { Regional Patients' } \\
\text { interests (PT18.5) } \\
\end{array}$ & & & \\
\hline $\begin{array}{l}\text { Diabetics Association } \\
\text { (PT18.6) }\end{array}$ & & & \\
\hline $\begin{array}{l}\text { Dutch Association for } \\
\text { Muscular Diseases } \\
\text { (PT18.7) } \\
\end{array}$ & & & \\
\hline $\begin{array}{l}\text { Dutch Association for } \\
\text { Regional Patients' } \\
\text { Interests (PT19.0) } \\
\end{array}$ & $\begin{array}{l}\text { Quality of care in } \\
\text { general practice }\end{array}$ & $14 ; 20 ; 41 ; 42$ & |11; 12 \\
\hline $\begin{array}{l}\text { Dutch Cystic Fibrosis } \\
\text { Foundation (PT21.0) } \\
\end{array}$ & $\begin{array}{l}\text { Quality visitations of } \\
\text { CF-centres }\end{array}$ & $21 ; 33 ; 42$ & 13 \\
\hline $\begin{array}{l}\text { Borderline Foundation } \\
\text { (PT22.0) }\end{array}$ & $\begin{array}{l}\text { Quality check from } \\
\text { patients' perspective of } \\
\text { personality disorder } \\
\text { guidelines. }\end{array}$ & $20 ; 21 ; 30 ; 42$ & 00 \\
\hline $\begin{array}{l}\text { National Participation } \\
\text { Centre (PT25.0) }\end{array}$ & $\begin{array}{l}\text { Observations and group } \\
\text { conversations in } \\
\text { rehabilitation centres }\end{array}$ & $21 ; 42$ & 00 \\
\hline
\end{tabular}


Peeters, M.G.P., Delnoij, D.M.J., Friele, R.D. Stronger, but not (yet) an equal. The use of quality improvement instruments and strategies by patient organisations in the Netherlands. Social Science \& Medicine: 2014, 115(aug), 56-63

\begin{tabular}{|c|c|c|c|}
\hline $\begin{array}{c}\text { Patient organisation } \\
\text { (project codes) }\end{array}$ & Selected projects & $\begin{array}{c}\text { Type of } \\
\text { instrument }^{\mathrm{a}}\end{array}$ & Strategies \\
\hline $\begin{array}{l}\text { Asthma and Lung } \\
\text { disease Patients } \\
\text { Association (PT26.1) }\end{array}$ & \begin{tabular}{|l|} 
Development of a \\
Consumer Quality Index \\
for asthma and chronic \\
obstructive pulmonary \\
disease \\
\end{tabular} & 20 & 11 \\
\hline $\begin{array}{l}\text { Heart and Vascular } \\
\text { Group (PT27.1) }\end{array}$ & \begin{tabular}{|l|} 
Development of a \\
Consumer Quality Index \\
for Heart Disease
\end{tabular} & 20 & $00 ; 11$ \\
\hline $\begin{array}{l}\text { Dutch Federation of } \\
\text { Cancer Patients } \\
\text { Associations (PT28.1) } \\
\end{array}$ & \begin{tabular}{|l|} 
Development of a basic \\
Consumer Quality Index \\
for cancer patients.
\end{tabular} & |20 & $00 ; 11$ \\
\hline $\begin{array}{l}\text { Asthma and Lung } \\
\text { disease Patients } \\
\text { Association (PT29.0) }\end{array}$ & \begin{tabular}{|l|} 
Development of Quality \\
Criteria for Asthma Care \\
from patients' \\
perspective.
\end{tabular} & 12; 14; 30 & 11 \\
\hline $\begin{array}{l}\text { Dutch Association for } \\
\text { Muscular Diseases } \\
\text { (PT31.1) }\end{array}$ & \begin{tabular}{|l|} 
Development of \\
Consumer Quality Index \\
modules for muscular \\
diseases.
\end{tabular} & | 21 & $00 ; 11$ \\
\hline $\begin{array}{l}\text { Dutch Association for } \\
\text { the Hearing Impaired } \\
\text { (PT39.1) }\end{array}$ & \begin{tabular}{|l|} 
Applying the Appliances \\
Consumer Quality Index \\
in the NVVS-guide \\
\end{tabular} & $21 ; 23$ & $10 ; 11$ \\
\hline $\begin{array}{l}\text { Rheumatics } \\
\text { Association (PT40.1) }\end{array}$ & \begin{tabular}{|l|} 
Applying the \\
Rheumatics Consumer \\
Quality Index in check \\
consumers' experiences \\
in rheumatology centres. \\
\end{tabular} & 20; 23; 33 & 12 \\
\hline $\begin{array}{l}\text { Asthma and Lung } \\
\text { disease Patients } \\
\text { Association (PT41.0) } \\
\end{array}$ & $\begin{array}{l}\text { Checking (regional) } \\
\text { health care purchase } \\
\text { contracts. }\end{array}$ & 30 & 00 \\
\hline
\end{tabular}

a

Type of instrument codes. $00=$ other. 10 = Category 1: Standardisation and standard setting (11 standards of care; 12 quality criteria; 13 guideline; 14 care purchase criteria). 20, 30 = Category 2: Consultation, comparison and checking (21 survey; 22 benchmark; 23 choice support; 31, 32 audit; 33 visitation; 35 quality marks, rating). 40 = Category 3: Negotiating and advising ( 41 purchase deals; 42 quality improvement negotiations). b

Strategy. $00=$ other. $10=$ Institutionalised method. $11=$ Scientization. $12=$ Good relationship. $13=$ Professionalising. $14=$ Sensitizing. 
Peeters, M.G.P., Delnoij, D.M.J., Friele, R.D. Stronger, but not (yet) an equal. The use of quality improvement instruments and strategies by patient organisations in the Netherlands. Social

Science \& Medicine: 2014, 115(aug), 56-63

\section{REFERENCES}

Alfords, 1975R. AlfordsHealth Care Politics, Ideological and Interest Group Barriers to ReformChicago University Press, Chicago (1975)

Arnstein, 1969S.R. ArnsteinA ladder of citizen participationJ. Am. Inst. Plan., 35 (1969), pp. 216-224

Bal, 2008R. BalDe Nieuwe Zichtbaarheid. Sturing in Tijden Van MarktwerkingRede Erasmus Universitair Medisch Centrum (2008)

Berk et al., 2008M. Berk, H.v.d. Steeg, G. SchrijversStille kennis. Patienten-en gehandicaptenorganisaties: Waardevolle bronnen van informatieUMC/Julius Centrum voor Gezondheidswetenschappen en Eerstelijnsgeneeskunde, Utrecht (2008)

Boivin et al., 2009A. Boivin, J. Green, J. van der Meulen, F. Légaré, E. NolteWhy consider patients' preferences? A discourse analysis of clinical practice guideline developersMed. Care, 47 (2009), pp. 1537-1948 (Electronic)

Bouman et al., 2008G.A. Bouman, B. Karssen, E.C. WilkinsonZorginkoop Heeft the Toekomst. Maar Vraagt Nog Een Flinke Inzet Van Alle Betrokken PartijenRaad voor Volksgezondheid en Zorg, Den Haag (2008)

Bovenkamp, 2010H.M.v.d. BovenkampThe Limits of Patient Power. Examining Active Citizenship in Dutch Health CareIBMG Erasmus University Rotterdam, Rotterdam (2010)

Bovenkamp et al., 2008H.M.v.d. Bovenkamp, K. Grit, R. Ballnventarisatie patiëntenparticipatie in onderzoek, kwaliteit en beleidlnstituut Beleid \& Management Gezondheidszorg, Rotterdam (2008)

Bovenkamp and Trappenburg, 2009H.M.v.d. Bovenkamp, M.J. TrappenburgReconsidering patient participation in guideline developmentHealth Care Anal., 17 (2009), pp. 198-216

Bovenkamp et al., 2010H.M.v.d. Bovenkamp, M.J. Trappenburg, K.J. GritPatient participation in collective healthcare decision making: the Dutch modelHealth Expect., 13 (2010), pp. 73-85

Broerse et al., 2010J. Broerse, L.v.d. Ham, S.v. Veen, C. Pittens, M.v TulderInventarisatie Patientenparticipatie Bij RichtlijnontwikkelingAthena Instituut, VU Amsterdam (2010)

Callahan, 2007K. CallahanCitizen participation: questions of diversity, equity and fairnessJ. Public Manag. Soc. Policy, Spring 2007 (2007), pp. 53-68

Coordinatieplatform-zorgstandaarden, 2010CoordinatieplatformzorgstandaardenZorgstandaarden in Model. Rapport over Het Model Voor Zorgstandaarden Bij Chronische Ziekten ZonMw ProgrammaDiseasemanagement chronische ziekten, Den Haag (2010)

Delnoij et al., 2010D.M. Delnoij, J.J. Rademakers, P.P. GroenewegeStakeholder involvement in the development of national indicator sets: the example of the Dutch Consumer Quality IndexEur. J. Public Health, 20 (2010), p. 13

Kamphuis et al., 2012H. Kamphuis, K. Hekkert, M. van Dongen, R. KoolFacts and figures about patient associations in the Netherlands between 2007 and 2009: review of their activities and aimsHealth Policy, 107 (2012), pp. 243-248

Koning et al., 2007J.D. Koning, A. Smulders, N. KlazingaAppraisal of Indicators through Research and Evaluation (AIRE)AMC/UvA, Amsterdam (2007)

Leahy et al., 2011M. Leahy, H. Löfgren, E.d LeeuwIntroduction - consumer groups and the democratization of health policyM. Leahy, H. Löfgren, E.d. Leeuw (Eds.), Democratizing Health. Consumer Groups in the Policy Process, Edward Elgar Publishing, Cheltenham/Northhampton (2011), pp. 1-14

Miller and Sarat, 1980-1981R.E. Miller, A. SaratGrievances, claims, and disputes: assessing the adversary cultureLaw Soc. Rev., 15 (1980-1981), pp. 526-565

Ministerie van Volksgezondheid, 2011W.e.S. Ministerie van VolksgezondheidBeleidskader voor subsidiëring van patiënten-en gehandicaptenorganisatiesW.e.S. Ministerie van Volksgezondheid (Ed.), Uitgangspunten subsidiemogelijkheden en beoordelingskader voor subsidieaanvragen. CONCEPTVERSIE, behorend bij de Visiebrief 'Bundel je kracht, samensterk', Rijksoverheid, Den Haag (2011) (MC-U-3065567), d.d. 25-05-2011 Ministerie VWS, 2008-2009Ministerie VWSSubsidiebeleid PGO VWS. Brief aan de Voorzitter van de Tweede Kamer der Staten-GeneraalKamerstuk (2008-2009) 29214, nr. 36 
Peeters, M.G.P., Delnoij, D.M.J., Friele, R.D. Stronger, but not (yet) an equal. The use of quality improvement instruments and strategies by patient organisations in the Netherlands. Social

Science \& Medicine: 2014, 115(aug), 56-63

Mol, 2006A. MolDe logica van het zorgen. Actieve patienten en de grenzen van het kiezenVan Gennip, Amsterdam (2006)

Nederland and Duyvendak, 2004T. Nederland, J.W. DuyvendakDe kunst van effectieve belangenbehartiging door de patiënten- en cliëntenbeweging. De praktijkVerwey-Jonker instituut, Utrecht (2004)

Nederland et al., 2003T. Nederland, J.W. Duyvendak et al.Belangenbehartiging door de patiënten-en cliëntenbeweging. De theorieVerwey-Jonker instituut, Utrecht (2003)

Nederland et al., 2007T. Nederland, D. Oudenampsen, S.t WoerdsEffectief beïnvloeden van zorgverzekeraars. Verkennende analyse van de rol van PGO-organisaties in een zorgstelsel met marktwerkingVerwey-Jonker Instituut, Utrecht (2007)

Peeters, 2007M.G.P. PeetersCompensatie en erkenning voor werknemers met asbestziekten tussen 1978 en 2005. Een rechtssociologisch onderzoekWolf Legal Publishers: Faculty of Law/Erasmus University Rotterdam, Nijmegen (2007)

Peper, 1998B. PeperSociale problemen en de moderne samenleving; een cultuursociologische beschouwingHet Spinhuis, Amsterdam (1998)

Raad voor Volksgezondheid en Zorg, 2010Raad voor Volksgezondheid en ZorgDe Patiënt Als Sturende KrachtRVZ, Den Haag (2010)

Schipaanboord et al., 2011A. Schipaanboord, D.M. Delnoij, R. BalPatient empowerment in the NetherlandsM. Leahy, H. Löfgren, E.d. Leeuw (Eds.), Democratizing Health. Consumer Groups in the Policy Process, Edward Elgar Publishing Limited, Cheltenham (2011), pp. 111-126

Schippers, 2011E.I.V.v.Z.-H., M.L.L.E. SchippersBundel je kracht, samen sterkW.e.S. Ministerie van Volksgezondheid (Ed.), Visiebrief beleidskader voor subsidiëring van patiënten- en gehandicaptenorganisaties aan Tweede Kamer der Staten-Generaal d.d. 2505-2011, Rijksoverheid, Den Haag (2011)

Sok et al., 2009K. Sok, E. Kok, T. Royers, B. PanhuijzenCliëntenparticipatie in Beeld. Inventarisatie Praktijkvoorbeelden Van CliëntenparticipatieMovisie/Vilans, Utrecht (2009) Stone, 2002D.A. StonePolicy Paradox. The Art of Political Decision MakingW.W. Norton \& Company, New York/London (2002)

Teunissen and Abma, 2010G.J. Teunissen, T.A. AbmaDerde partij: tussen droom en daad. Een verkennend onderzoek naar de patiëntenpartij en-criteria voor onderzoek, beleid en kwaliteit bij overheden en zorginstellingenTSG, 88 (2010), pp. 182-189

Trappenburg and Bovenkamp, 2008M. Trappenburg, H.v.d BovenkampGenoeg is genoeg. Over gezondheidszorg en democratieAmsterdam University Press, Amsterdam (2008)

Tritter, 2006J.Q. TritterThe snakes and ladders of user involvement: moving beyond Arnstein Health Policy, 76 (2006), pp. 156-168

Victoor et al., 2012A. Victoor, R.D. Friele, D.M.J. Delnoij, J.J.D.J.M. RademakersFree choice of healthcare providers in the Netherlands is both a goal in itself and a precondition: modelling the policy assumptions underlying the promotion of patient choice through documentary analysis and interviewsBMC Health Serv. Res., 12 (2012), p. 441

Williamson, 2008C. WilliamsonAlford's theoretical political framework and its application to interests in health care nowBr. J. Gen. Pract., 58 (2008), pp. 512-516

Williamson, 2010C. WilliamsonTowards the Emancipation of Patients. Patients' Experiences and the Patient MovementThe Policy Press, Bristol (2010)

Winter and Steger, 1998M. Winter, U. StegerManaging Outside PressureJohn Wiley \& Sons, Chichester (a.o.) (1998)

Zuidgeest, 2011M. ZuidgeestMeasuring and Improving the Quality of Care from the Healthcare User Perspective: the Consumer Quality IndexUniversity of Tilburg, Tranzo, Tilburg (2011) 